\title{
Measurement of Ultrasonic Velocity and Attenuation Coefficient on Cell Density and Disruption of Aspergillus Niger
}

\author{
Srinivasa Reddy $\mathrm{M}^{1}$, Linga Reddy $\mathrm{D}^{2}$ \\ ${ }^{1}$ Department of Physics, Anurag Group of Institutions, Venkatapur, Hyderabad, India \\ ${ }^{2}$ Deptartment of Physics, UCS, Osmania University, Hyderabad, India. \\ E mail : srmainampati@gmail.com,dlreddy_phy@yahoo.com
}

\begin{abstract}
The present study envisaged the measurement of ultrasonic velocity and attenuation coefficient on cell density of A.niger by using novel Pulse Echo Overlap (PEO) technique. The author reported parameters like acoustic impedance, adiabatic compressibility and free length were computed by applying Jacobson's Free Length Theory (FLT). The cell density was carried out by using hemocytometer. The ultrasound transducer of $10 \mathrm{~mm}$ gap between transmitting and reflecting surfaces was immersed into the sonication vessels which were filled with varied cell density of $10^{1}$ to $10^{8}$ per $\mathrm{ml}$ to measure ultrasonic parameters for 2 and $10 \mathrm{MHz}$ ultrasound. The sonication vessel kept inside the water bath to maintain constant environmental temperature of $303 \mathrm{~K}$ by using automatic temperature controlled bath. In addition, the cell disruptions were carried out at 2 and 10 MHz high power ultrasound of output power of 600 watts by using ultrasonic processor. The ultrasonic velocity and attenuation coefficient were measured simultaneously with disruption of cell density as a function of sonication time. The uncertainty in measuring of ultrasonic velocity $(v)$ is $\pm 0.02 \%$ and the attenuation coefficient $(\alpha)$ is $\pm 0.0015 \%$. It was observed that both ultrasonic velocity and attenuation coefficient linearly increased with increasing concentration of cells. It was reported that the increased ultrasonic velocity was due to decreased adiabatic compressibility and free length with increased cell density. It was investigated that the attenuation coefficient was high at $10 \mathrm{MHz}$ than $2 \mathrm{MHz}$ high absorption losses occurred at $10 \mathrm{MHz}$. It was concluded that ultrasound waves propagated through culture of A.niger disturb the equilibrium between cells presented in the suspension and this retarded equilibrium shifts between the number of cells and their sizes and shapes, in turn, the ultrasound velocity and absorption.
\end{abstract}

Keywords: Pulse Echo Overlap (PEO) technique, Ultrasound, A.niger, ultrasonic velocity and attenuation coefficient

\section{INTRODUCTION}

In the recent years, the measurement of ultrasonic velocity and attenuation coefficient has been adequately employed in understanding biological effects induced by ultrasound in macromolecules, microorganisms, tissues, organs and bones etc. Beside widespread well established studies of ultrasonic velocity and attenuation coefficient of biological materials in basic research, more recently the adiabatic compressibility and intermolecular free length has also been considered as an indicator with high potential in the advanced medical diagnoses and as a process control parameter in the food industry [1-3].
The lot of research has been carried out by researchers dealt with disruption and inactivation of microbes depending upon the power, pressure and frequency applied through a number of physical, mechanical and chemical effects arising from acoustic cavitations [4-6].

Resistance of different species to ultrasound differed widely which was because specific effect of ultrasound on the cell wall and differences in the cell wall structures among species [7]. Bacterial spores were much more resistant than vegetative ones and fungi were more resistant in general than vegetative bacteria [8]. Since molds and yeasts were in general more resistant to high intensity ultrasound [9], and not enough information about mold spores was available.

It has been reported that the velocity of an ultrasound wave through a medium varies with the physical properties of the medium. Liquids exhibit ultrasound velocities intermediate between those in gases and solids. With the notable exceptions of lung and bone, biologic tissues yield velocities roughly similar to the velocity of ultrasound in liquids. In different media, changes in velocity were reflected in changes in wavelength of the ultrasound waves, with the frequency remaining relatively constant [10].

The velocity of sound was determined by the density $(\rho)$ and compressibility $(\mathrm{K})$ of the medium. In a given volume the amount of material was equals to density and compressibility was a measure of how much a substance could be compacted for a given pressure. The velocity of sound in a medium can be determined by the equation $v=(\mathrm{K} \rho)^{-1 / 2}$

Where $v$ is the speed of sound, $\mathrm{K}$ is the compressibility, and $\rho$ (rho) is the density.

The various forms of interaction between ultrasonic waves and particles were necessary to understand how ultrasound can be used to characterize microbes [11-12]. The four most important types of interaction between an ultrasonic waves and a colloidal dispersion of microbes were intrinsic absorption, visco-inertial dissipation losses, thermal dissipation losses and scattering losses.

The colloidalsuspension consists of large number of individual components. The phase of each component absorbs ultrasound as a result of classical(viscous and thermal) and relaxation loss mechanisms. These losses were determined by the composition ofthe suspension, rather than by its microstructure. 
Especially, there were two major classes of attenuation mechanisms were observed in ultrasonic materials characterization. The primary, absorption converts acoustic energy into heat via viscosity, relaxation, heat conduction, elastic hysteresis, etc. The absorbed energy was irreversibly lost from the acoustic field since it was dissipated in the medium. The secondary, scattering converts the energy of the coherent, collimated beam into incoherent, divergent waves as a result of wave interaction with in-homogeneities in the material.

To a first approximation, the overall attenuation coefficient of a colloidal suspension of microbes can be considered to be the sum of these various contributions (although in reality some of these mechanisms were coupled to each another). In most suspensions, one or two of the above mechanisms usually dominate the overall attenuation in a particular frequency range.

Aspergillus niger was chosenas representative species. In terms of ultrasonic measurements more research is necessary to understand their use to estimate cell density and disruptive applications in food industry,especially for fungi. The purpose of this research was aimed to measure density, ultrasonic velocity, attenuation coefficient, and evaluatescompressibility, free length and acoustical impedance as a function of cell density and sonication time.

\section{MATERIALS AND METHODS}

\section{A. Sample Collection}

The samples were isolated from the effected rice seed; rice bran, wheat bran and cheese were collected in sterilized screw capped bottles and transported to the Advanced Microbiology Laboratory, University College of Technology. The samples were stored under refrigeration conditions for conducting different experiments.

\section{B. Sample Preparation}

The water suspensions used for isolation were prepared by dipping the samples in pre-sterilized distilled water.

\section{Media Preparation}

The selected media such as potato dextrose agar (PDA) and potato dextrose broth (PDB), used for fungal development were prepared according to the methods suggested by Harrigan (1998). The $\mathrm{pH}$ of media was adjusted by using $0.1 \mathrm{~N} \mathrm{NaOH}$ and $0.1 \mathrm{~N} \mathrm{HCl}$.

\section{i. Potato Dextrose Broth}

The $1 \mathrm{~L}$ of distilled water was used to boil diced potatoes for 1 hour and then filtered through muslin cloth. The volume of filtrate was made upto $1000 \mathrm{~mL}$ and then glucose was added. The sterilization of medium was done by autoclaving.

\begin{tabular}{ll}
\hline \multicolumn{2}{l}{ Composition of potato dextrose broth } \\
\hline Ingredients & Quantity \\
$\begin{array}{l}\text { Potatoes peeled and diced } \\
\text { into small pieces }\end{array}$ & $200 \mathrm{~g}$ \\
Glucose & $20 \mathrm{~g}$ \\
\hline Distilled water & $1000 \mathrm{~mL}$ \\
\hline
\end{tabular}

\section{ii. Potato Dextrose Agar}

The potato dextrose broth (PDB) was converted into potato dextrose agar (PDA) by adding 1.5\% agar-agar and then sterilized by autoclaving.

\section{Inoculation and Incubation}

The samples (water suspensions) were first inoculated on to the PDA and incubated at $30^{\circ} \mathrm{C}$ for $72-96$ hours and growth pattern was studied according to the suggestions and methods of Harrigan (1998). The selected colonies from PDA were further transferred to PDB for growth of cells.

\section{E. Identification of Aspergillus Niger}

Aspergillus niger was identified on the basis of morphology and growth pattern according to the methods recommend by Harrigan (1998). It was based on generalexamination of growth pattern of mycelia and spores under microscope after staining.

\section{F. Ultrasonic Measurement Studies}

Firstly, the $10 \mathrm{~mL}$ potato dextrose broth (without inoculum) was poured into the sonication vessel (control)(15 ml glass bottles, internal diameter $21 \mathrm{~mm}$, flat base, $2.5 \mathrm{~mm}$ wall thickness). Next, the low power (2 $\mathrm{mW})$ ultrasonic transducer of $10 \mathrm{~mm}$ gap between transmitting and reflecting surfaces was immersed into the vessel. The other end of the transducer is connected to the ULTRASONIX 4400M (fabricated and supplied by Roop Telsonic Ultrasonix Limited, Mumbai.) by BNC cable and Pulse Echo pattern was observed on the CRO screen which was used to measure delay time and attenuation. Further the selected cells of A.niger from PDA inoculated into the $10 \mathrm{~mL}$ PDB which were poured into the sonication vessels with cell density ranging from $10^{1}$ to $10^{8}$ cells $/ \mathrm{ml}$ insteps of $10^{1}$ increments. For each cell density ultrasonic velocity and attenuation coefficient measurements were repeated for six times and average values were reported in tables. The sonication vessel kept inside the water bath upto its neck and the temperature of the water bath was maintained at constant temperature of $303 \mathrm{~K}$ with aid of automatic temperature control unit.

\section{G. Ultrasonic Disruptive Studies}

For the ultrasound irradiation purpose the control samples (without sonication) of A.niger cultures were selected with $10^{7}$ cell $/ \mathrm{ml}$.PDB inoculated $10^{7}$ cell $/ \mathrm{ml}$ took into the different number of sonication vessels $(15 \mathrm{ml}$ glass bottles, internal diameter $21 \mathrm{~mm}$, flat base, $2.5 \mathrm{~mm}$ wall thickness to a depth of $25 \mathrm{~mm}$ ) of $10 \mathrm{ml}$ each exposed to ultrasound for a period of $1 \mathrm{~min}$ to maximum of 6 min at 2 $\mathrm{MHz}$ and $1 \mathrm{~min}$ to maximum of $8 \mathrm{~min}$ at $10 \mathrm{MHz}$ by using ultrasonic-processor (model USG - 600) series and an output power of $600 \mathrm{~W}$ i.e. $60 \mathrm{~W} / \mathrm{ml}$. Throughout the study a sonotrode of $12 \mathrm{~mm}$ diameter of titanium probe set at 5 $\mathrm{mm}$ below the surface of the culture was used. After sonication, the densities of viable cells were counted by using hemocytometer. The measurements were repeated at each sonication minute for six times and average values were reported in the tables. 


\section{H. Ultrasonic Velocity Measurements}

The novel Pulse Echo Overlap (PEO) technique was introduced to measure ultrasonic parameters in PDB of A.niger. The ultrasonic transducer was immersed in PDB. It generates a pulse of ultrasound which travelled across the sample, was reflected from the bottom wall of the measurement cell, travels back through the sample, and was then detected by the same transducer.The single transducer was used to both transmit and receive ultrasonic pulses. The ultrasound velocity in the medium was found from the measured delay time difference $(\Delta t)$ and earlier found length of the measurement chamber $(d)$.

$$
v=\frac{2 d}{\Delta l} \mathrm{~cm} / \mathrm{sec}
$$

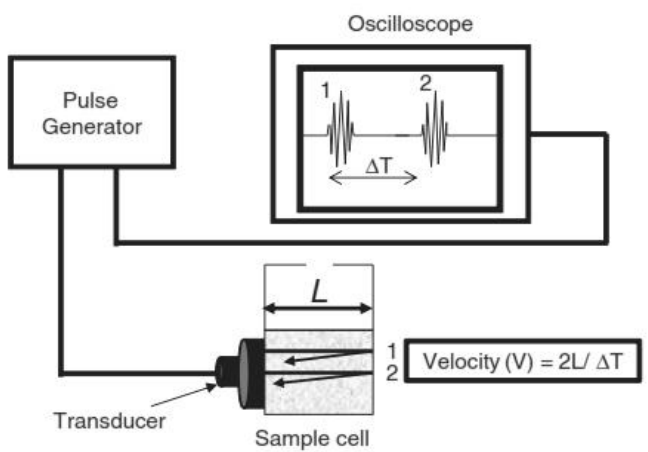

Figure 1. Schematic representation of Ultrasonic velocity measurements

The uncertainty in velocity measurements by this technique were $\pm 0.02 \%$.

\section{Attenuation Coefficient Measurements}

The multiple reflections of ultrasound pulses in the sample produced consecutive echoes which were observed on CRO screen. The attenuation coefficients of the fungal cultures were carried out by measuring the amplitudes of transmitted pulses of selected two successive echoes on CRO screen. The ultrasonic attenuation coefficient was calculated by using the following formula.

$$
\alpha=\frac{1}{2 l} \ln \left(\frac{A_{n}}{A_{n+1}}\right)
$$

nep/cm

Where $2 l$ was distance travelled and $A_{n} / A_{n+1}$ was the ratio between two successive echoes of $A_{n}$ and $A_{n+1}$. The uncertainty in attenuation coefficient $(\alpha)$ measurements were $\pm 0.0015 \%$.

\section{J. Measurement of Cell Density}

The fungal cells were counted with the help of Hemocytometer. The microscope at $100 \mathrm{x}$ magnification was used to view the spores. Under the microscope, grids of 9 squares were identified. After that, focus the microscope on one of the 4 outer squares in the grid. The each square should contain 16 smaller squares. Then, Count all the spores in the four $1 \mathrm{~mm}$ corner squares. If there are too many or few spores to count, repeat the procedure either concentrating or diluting the original suspension as appropriate.

Viable cells $/ \mathrm{ml}=$ Average viable cells count per square $\mathrm{x}$ Dilution Factor.

\section{K. Density Measurements}

The bicapillary Pyknometer of $10 \mathrm{ml}$ volume was used to find density of bacteria cultures. The micro pipette was adapted to transfer A.niger cultures to PDB in the laminar flow chamber to avoid contamination with air and body.The density of bacteria cultures was measured by using the following procedure

Mass of the empty bicapillary pyknometer $=\mathrm{w}_{1} \mathrm{gm}$

Mass of the bacteria culture + pyknometer $=w_{2} \quad \mathrm{gm}$

Mass of the culture $(\mathrm{m})=\mathrm{w}_{2}-\mathrm{w}_{1} \mathrm{gm}$

Volume of the culture $=\mathrm{V} \mathrm{cm}^{3}$

Density of the bacteria culture $(\rho)$

$=\quad \frac{\text { Mass of the culture }(m)}{\text { Volume of the culture }(V)} \quad \mathrm{gm} / \mathrm{cm}^{3}$

The accuracy in measuring density of bacteria cultures was 2 parts in $10^{5}$.The single pan electrical balance was used to find the masses of the samples. The accuracy of measuring the masses was $\pm 0.01 \mathrm{mg}$.

\section{Computed Parameters}

\section{i. Compressibility $(\beta s)$}

The compressibility can be calculated as $\beta_{\mathrm{s}}=1 / \rho \mathrm{v}^{2} \quad \mathrm{~cm}^{2} /$ dynes

Herepwas the density and was the ultrasonic velocity

$$
\text { ii. Free Length }(L f)
$$

The free length wascalculated by substituting compressibility in below equation

$$
\mathrm{L}_{\mathrm{f}}=\mathrm{K} \quad 1 \quad \text { A.U. ------ (6) }
$$

Where K was Jac $\$$ son's temperature constant was $=631 \mathrm{x}$ $10^{-6}$ at $303 \mathrm{~K}$

\section{iii. Acoustical Impedance (z)}

The equation to calculate acoustical impedance is

$$
Z=\rho v
$$

Where $\rho$ was the density and $v$ was the ultrasonic velocity

\section{RESULT AND DISCUSSIONS}

The variation of density and ultrasonic parameters with cell density were reported in the table 1. Figure 2 showed that density exponentially increased and ultrasonic velocity linearly increased with increasing cell density. The adiabatic compressibility and free length decreased exponentially with increasing cell density as shown in figure 3. It was observed that as the number of cells increasing in culture might be the reason to increase density. As we know that free length between the cells might be decreased with increased density of culture and in turn caused to decrease compressibility. It was investigated that the decreased compressibility of culture with increased 
cell density could be the primary reason for the increased ultrasonic velocity.

Figure 4 showed that the variation of attenuation coefficient at 2 and $10 \mathrm{MHz}$ with increasing cell density was followed the linear path, because at low cell concentration the attenuation coefficient was only due to absorption losses, as the concentration of cells increased in the suspension, the scattering losses were initiated due to availability of more and more scatters. It was reported that the visco-internal and thermal loss mechanisms usually dominateat nearly low frequencies, but the intrinsic absorption and scattering losses usually dominateat relatively higher frequencies. Usually absorption losses were directly proportional to square of frequency in liquids due to this attenuation was reported more at $10 \mathrm{MHz}$ than 2 $\mathrm{MHz}$ for A.niger. Therefore, in general attenuation coefficient at $10 \mathrm{MHz}$ was reported greater than $2 \mathrm{MHz}$. It was observed that the variation of attenuation coefficient was more happened at $2 \mathrm{MHz}$ than $10 \mathrm{MHz}$ because scattering losses were inversely proportional to cell size of A.niger.

The density and ultrasonic parameters variations as a function of sonication time were reported in table 2. It was observed that density suddenly fell after few minutes of sonication time because cell density in PDB rapidly decreased with sonication time (Figure 5). Figure 6 showed that the ultrasonic velocity linearly decreased with increased sonication time. It was found that the sonication time required to bring the ultrasonic velocity to minimum value was less at $2 \mathrm{MHz}$ than $10 \mathrm{MHz}$ because the cavitation effect was more at $2 \mathrm{MHz}$ than $10 \mathrm{MHz}$. It was investigated that the formation of transient cavitation occurred early at $2 \mathrm{MHz}$ than $10 \mathrm{MHz}$ which was held responsible for cell disruption. The variation of ultrasonic velocity with sonication time was also confirmed linearly increased compressibility and free length of suspension with sonication time.

It was observed that attenuation coefficients were almost linearly decreased with sonication time (Figure 9). It was found that with increased sonication time the numbers of cells present in PDB were decreased linearly (Figure 10). It was reported that the scattering losses were decreased with reduced numbers of cells present in PDB and hence attenuation coefficient.

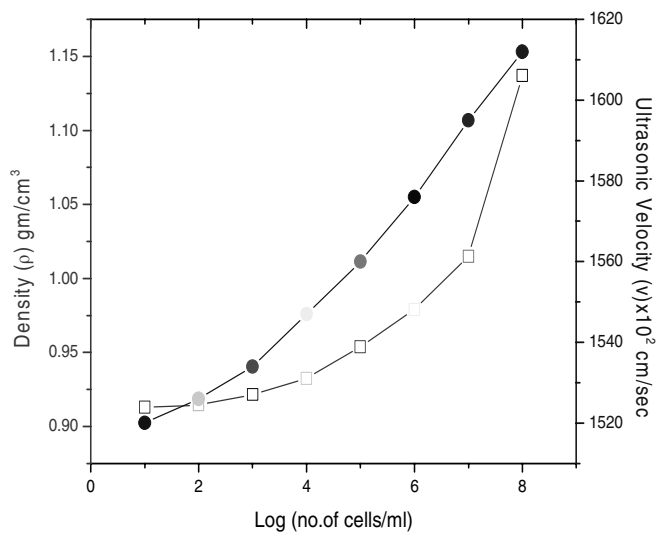

Figure 2. Graphic representation of density and ultrasonic velocity with cell density

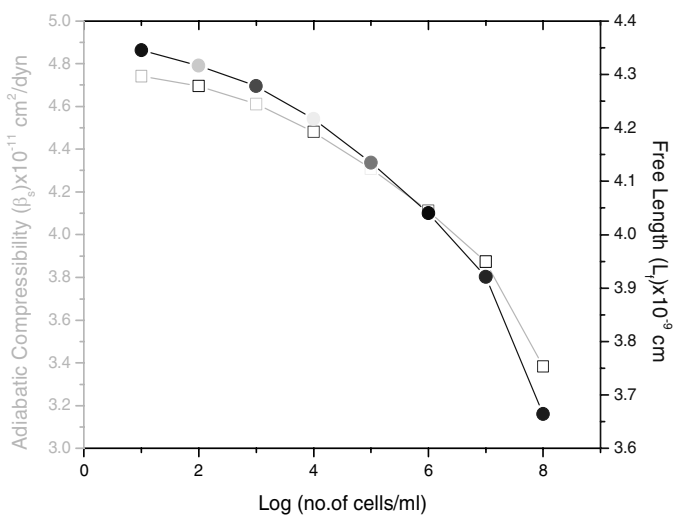

Figure 3. Graphic presentation of adiabatic compressibility and free length as a function of cell density

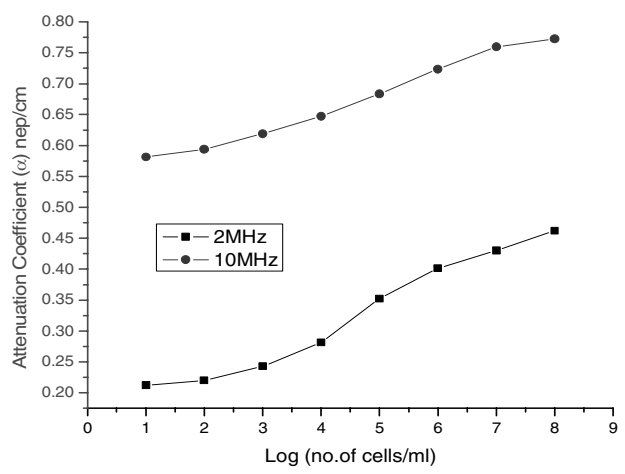

Figure 4. Comparison of attenuation coefficient as function of cell density

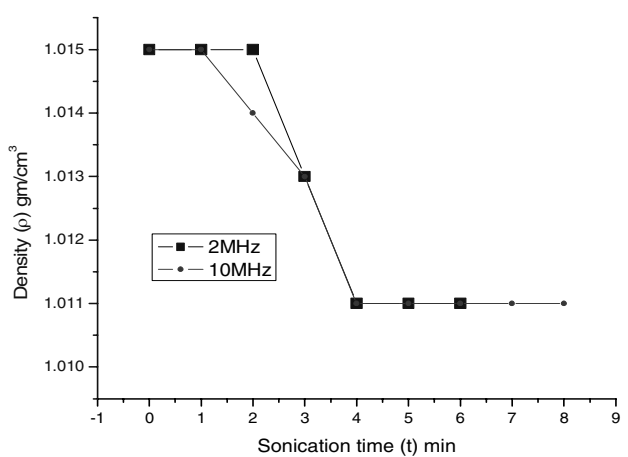

Figure 5. Comparison of density as a function of sonication time

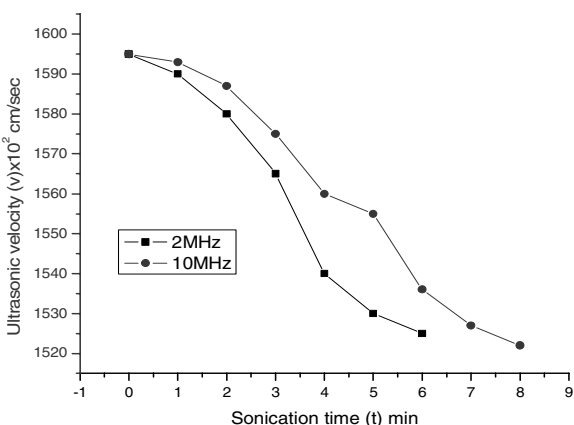

Figure 6. Comparison of ultrasonic velocity as a function of sonication time 


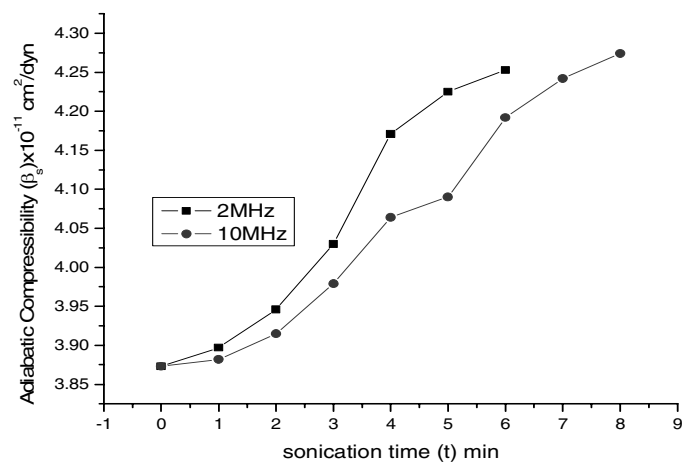

Figure 7. Comparison of adiabatic compressibility as a function of sonication time

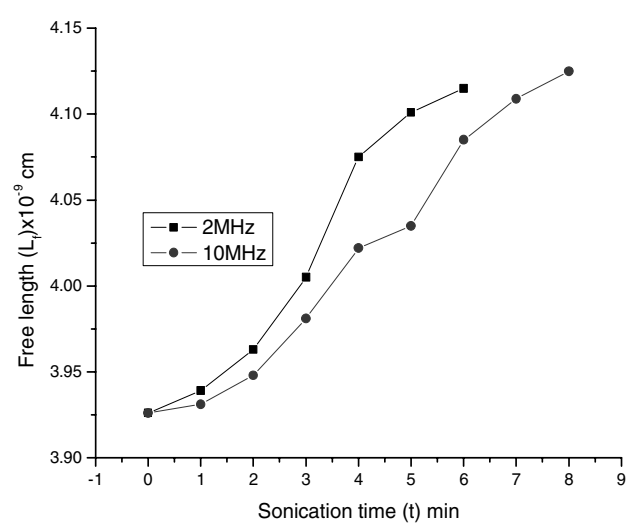

Figure 8. Comparison of free length as function of sonication time

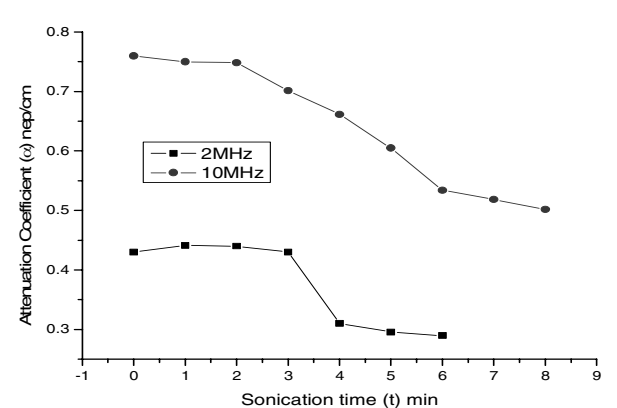

Figure 9. Comparison of attenuation coefficient as a function of sonication time

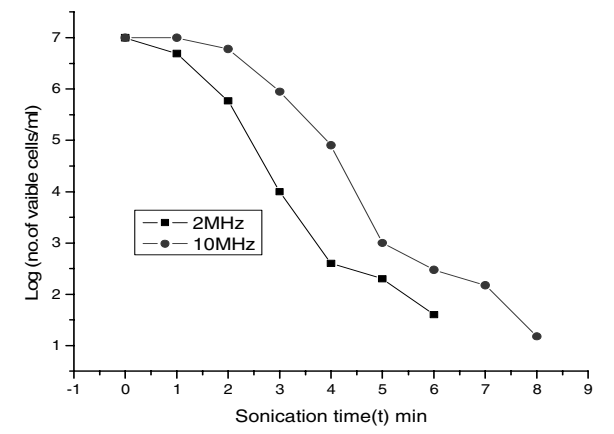

Figure 10. Comparison of no. of viable cells as a function of sonication time

Table1: The Number of spores per ml, Density, Ultrasonic velocity, Adiabatic compressibility, free length, Attenuation coefficient and Acoustical Impedance of Aspergillus Niger at $303 \mathrm{~K}$.

\begin{tabular}{|c|c|c|c|c|c|c|c|}
\hline \multirow[t]{2}{*}{ No.of cells $/ \mathrm{ml}$} & \multirow{2}{*}{$\begin{array}{l}\text { Density (目) } \\
\left(\mathrm{gm} / \mathrm{cm}^{3}\right)\end{array}$} & \multirow{2}{*}{$\begin{array}{c}\text { Ultrasonic } \\
\text { Velocity }(\mathrm{v}) \times \\
10^{2} \mathrm{~cm} / \mathrm{sec}\end{array}$} & \multirow{2}{*}{$\begin{array}{c}\text { Adia.Comp } \\
\left(\beta_{\mathrm{s}}\right) \times 10^{-11} \\
\mathrm{~cm}^{2} / \mathrm{dyn}\end{array}$} & \multirow{2}{*}{$\begin{array}{l}\text { Free length }\left(\mathrm{L}_{\mathrm{f}}\right) \\
\quad \mathrm{X} 10^{-9} \mathrm{~cm}\end{array}$} & \multicolumn{2}{|c|}{$\begin{array}{c}\text { Attenuation Coefficient }(\alpha) \\
\text { nep/cm }\end{array}$} & \multirow[t]{2}{*}{$\begin{array}{l}\text { A. I. }(\mathrm{z}) \times 10^{5} \\
\mathrm{gm} / \mathrm{cm}^{2}-\mathrm{sec}\end{array}$} \\
\hline & & & & & $2 \mathrm{MHz}$ & $10 \mathrm{MHz}$ & \\
\hline $10^{1}$ & 0.9129 & 1520 & 4.741 & 4.345 & 0.2125 & 0.5815 & 1.387 \\
\hline $10^{2}$ & 0.9145 & 1526 & 4.695 & 4.316 & 0.2200 & 0.5941 & 1.395 \\
\hline $10^{3}$ & 0.9216 & 1534 & 4.611 & 4.278 & 0.2431 & 0.6189 & 1.413 \\
\hline $10^{4}$ & 0.9324 & 1547 & 4.481 & 4.217 & 0.2815 & 0.6472 & 1.442 \\
\hline $10^{5}$ & 0.9538 & 1560 & 4.308 & 4.135 & 0.3524 & 0.6834 & 1.487 \\
\hline $10^{6}$ & 0.9789 & 1576 & 4.113 & 4.040 & 0.4013 & 0.7236 & 1.542 \\
\hline $10^{7}$ & 1.015 & 1595 & 3.873 & 3.921 & 0.4301 & 0.7597 & 1.618 \\
\hline $10^{8}$ & 1.137 & 1612 & 3.384 & 3.664 & 0.4621 & 0.7723 & 1.832 \\
\hline
\end{tabular}


Table 2: Sonication time, Density, Ultrasonic velocity, Adiabatic compressibility, free length, Attenuation coefficient, Acoustical Impedance and Number of viable spores per $\mathrm{ml}$ of A.niger

\begin{tabular}{|c|c|c|c|c|c|c|c|}
\hline $\begin{array}{l}\text { Sonication } \\
\text { time (t) min. }\end{array}$ & $\begin{array}{c}\text { Density } \\
(\mathrm{gm} / \mathrm{cm} 3)\end{array}$ & $\begin{array}{c}\text { Ultrasonic } \\
\text { Velocity }(\mathrm{v}) \times \\
102 \mathrm{~cm} / \mathrm{sec}\end{array}$ & $\begin{array}{l}\text { Adia.Comp } \\
(\beta \mathrm{s}) \text { X 10- } \\
11 \mathrm{~cm} 2 / \mathrm{dyn}\end{array}$ & $\begin{array}{l}\text { Free length } \\
\text { (Lf)X 10-9 } \\
\mathrm{cm}\end{array}$ & $\begin{array}{c}\text { Attenuation } \\
\text { Coefficientne } \\
\text { p/cm }\end{array}$ & $\begin{array}{l}\text { A.I. }(\mathrm{z}) \times 105 \\
\mathrm{gm} / \mathrm{cm} 2-\mathrm{sec}\end{array}$ & $\begin{array}{l}\text { Number of } \\
\text { viable } \\
\text { cells } / \mathrm{ml}\end{array}$ \\
\hline 0 & 1.015 & 1595 & 3.873 & 3.926 & $0.4301 / 0.7597$ & 1.618 & 107 \\
\hline \multicolumn{8}{|l|}{$2 \mathrm{MHz}$} \\
\hline 1 & 1.015 & 1590 & 3.897 & 3.939 & 0.4412 & 1.613 & $5 \times 106$ \\
\hline 2 & 1.015 & 1580 & 3.946 & 3.963 & 0.4400 & 1.603 & $6 \times 105$ \\
\hline 3 & 1.013 & 1565 & 4.03 & 4.005 & 0.4302 & 1.585 & 104 \\
\hline 4 & 1.011 & 1540 & 4.171 & 4.075 & 0.3100 & 1.556 & 400 \\
\hline 5 & 1.011 & 1530 & 4.225 & 4.101 & 0.2956 & 1.546 & 200 \\
\hline 6 & 1.011 & 1525 & 4.253 & 4.115 & 0.2898 & 1.541 & 40 \\
\hline \multicolumn{8}{|l|}{$10 \mathrm{MHz}$} \\
\hline 1 & 1.015 & 1593 & 3.882 & 3.931 & 0.75 & 1.616 & 107 \\
\hline 2 & 1.014 & 1587 & 3.915 & 3.948 & 0.7485 & 1.609 & $6 \times 106$ \\
\hline 3 & 1.013 & 1575 & 3.979 & 3.981 & 0.7015 & 1.595 & $9 \times 105$ \\
\hline 4 & 1.011 & 1560 & 4.064 & 4.022 & 0.6615 & 1.577 & $8 \times 104$ \\
\hline 5 & 1.011 & 1555 & 4.09 & 4.035 & 0.605 & 1.572 & 1000 \\
\hline 6 & 1.011 & 1536 & 4.192 & 4.085 & 0.5341 & 1.552 & 300 \\
\hline 7 & 1.011 & 1527 & 4.242 & 4.109 & 0.5187 & 1.543 & 150 \\
\hline 8 & 1.011 & 1522 & 4.274 & 4.125 & 0.5019 & 1.537 & 15 \\
\hline
\end{tabular}

\section{CONCLUSIONS}

It was concluded that the ultrasonic velocity and attenuation coefficient strongly depends on cell size and number of cell present in PDB. It was hypothesized that scattering losses were occurred more at $2 \mathrm{MHz}$ than 10 $\mathrm{MHz}$ for A.niger. It was learnt that the data of ultrasonic parameters could be used to estimate the fungal cell density. It was also learnt that the variation of ultrasonic parameters with sonication time could be used for image production.

\section{REFERENCES}

[1] Srinivasa Reddy. M and Linga Reddy. D, "Ultrasonic dosimetry studies in microbial growth periods - synergies of $2 \mathrm{MHz}$ and $10 \mathrm{MHz}$ ultrasonic frequencies," IntInt. Journal of Research in Biochemistry and Biophysics,Vol.3(3) , p 21-28, 2013.

[2] Koward.W.Nowak et al., "A comparison of methods for the determination of sound velocity in biological materials: A case study", Ultrasonics, Vol. 53, pp. 923-927, 2013.
[3] T.S. Awad and H.A. Moharram, et.al. , "Applications of ultrasound in analysis, processingand quality control of food:A review," Food Research International,vol. 48, pp. 410-427, 2012.

[4] William. G and Aaron Ross. S, " Ultrasound increases the rate of Bacterial cell growth," BiotechnolProg, vol. 19(3), pp. 1038-1044, 2003.

[5] K. Sathi Reddy, Y.HariBabu, M. K. Tandle and D.Linga Reddy, "Ultrasonic Studies on the different veterinary Samples," J. Bioscience, Biotechnology Research Asia, vol. 4 (2), pp. 777-780, 2007.

[6] Srinivasa Reddy. M and Linga Reddy. D, "Investigation of Ultrasonic Parameters on Disruption of S.epidermidis at Ultrasound exposure of $20 \mathrm{kHz}$ and $36 \mathrm{kHz}$ frequencies," Proceedings of $20^{\text {th }}$ National Symposium on Ultrasonics (NSU - XX), ISBN 97881-926579-1-2, pp 88-93, 2014. 
[7] Earnshaw, R. G. , “ Ultrasound a new opportunity for foodpreservation", Ultrasoundin food processing, pp. 183192, 1998.

[8] Alliger, H., “ Ultrasonic disruption”, American Laboratory, vol.10, pp.75-85, 1975.

[9] Guerrero, S., Lopez-Malo, A., \&Alzamora, S. M., “ Effect of ultrasound on the survival of Saccharomyces cerevisiae: influence oftemperature, $\mathrm{pH}$ and amplitude" Innovative Food Science andEmerging Technologies, vol. 2, pp.31-39, 2001.

[10] Voleišiene, A. Voleišis, "Ultrasound velocity measurements in liquid media" ULTRAGARSAS
(ULTRASOUND), Vol. 63 (4), pp 7-19, 2008.

[11] U. Kaatze, B.K. Lautscham, `Acoustic Absorption Spectroscopy of Liquids between 0.15 and $3000 \mathrm{MHz}$ : II. Hypersonic ComparatorTechnique', J. Phys. E., 21, 402ะ406, 1988 .

[12] Kertzfield, K., and Litovitz, T. Absorption and Dispersion of Ultrasonic Waves. New York, Academic Press, 1959.

[13] N. Bilaniuk and G. S. K. Wong, J. Acoust. Soc. Am., vol. 93, pp.1609-12, 1993. 